12. Абрамян М.Э. 1000 задач по программированию. Ч. І. Скалярные типы данных, управляющие операторы, процедуры и функции. Ростов-на-Дону: Изд-во РГУ, 2004. 43 с.

13. Мезенцев А.В. Сборник задач по программированию с примерами. Иркутск: Иркутский государственный университет, 2011. 36 с.

14. Златопольский Д.М. Сборник задач по программированию. СПб.: БХВ-Петербург, 2011. 304 с.

15. Гребнева Д.М. Проектирование содержания курса «Основы робототехники» для студентов педагогических вузов // Современные наукоемкие технологии. 2014. № 12-2. С. 313-316.

16. Бунаков П.Ю., Лопатин А.К. Формирование компетентности будущих учителей информатики в области программирования // Современные информационные технологии в образовании: мат-лы XXVIII междунар. конф. Троицк-М.: Московский издательско-полиграфический колледж им. И. Федорова, 2017. С. 321-323.

17. Газейкина А.И. Обучение программированию будущего учителя информатики // Педагогическое образование в России. 2012. № 5. С. 45-48.
18. Слинкин Д.А. Использование метода проектов при обучении программированию в курсе информатики: дис. ... канд. пед. наук. Екатеринбург, 2001. 167 с.

19. Беленкова М.А., Рожина И.В. Формирование у будущих учителей информатики компетенции в области проектной деятельности // Актуальные вопросы преподавания математики, информатики и информационных технологий. 2015. № 1. С. 67-71.

20. Дятлова Л.И. Метод проектов в подготовке специалистов в сфере информационных технологий и программирования // Профессиональное образование и рынок труда. 2014. № 5. С. 20-21.

21. Лапчик М.П., Федорова Г.А. Инновационный подход к подготовке педагогических кадров в области информатизации образования // Преподаватель XXI век. 2016. № 4-1. С. 28-41.

22. Конова Е.А., Поллак Г.А. Обучение программированию с использованием метода кейсов // Совет ректоров. 2012. № 2. С. 57-63.

23. Юрьева Т.А., Чалкина Н.А., Лебедь О.А. Применение кейс-метода в обучении бакалавров основам программирования // Педагогические науки. 2016. № $7.78-82$.

\title{
TRAINING PROGRAMMING TO PROSPECTIVE IT TEACHERS: TASKS WITH A SPIRAL-INCREASING COMPLEXITY
}

(C) 2019

Pugach Valeriy Isaakovich, doctor of pedagogical sciences,

professor of Computer Science, Applied Mathematics and Teaching Methods Department

Tyuzhina Irina Viktorovna, candidate of pedagogical sciences, associate professor of Computer Science, Applied Mathematics and Teaching Methods Department

Makarova Elena Leonidovna, candidate of pedagogical sciences, associate professor of Computer Science, Applied Mathematics and Teaching Methods Department Samara State University of Social Sciences and Education (Samara, Russian Federation)

Abstract. This paper discusses one of the urgent problems of prospective IT teachers' training - the development of a special competence: the ability to use the programming methodology for solving tasks of the school «Computer Science» course. In contrast to the classical approach in teaching methods, when each topic under the section «Programming» is fixed by the solution of a number of simple tasks, we propose to solve problems with spirally increasing complexity (such tasks will be understood as large projects, the implementation of which can be improved throughout the study of the programming course, while at each stage the result of the work will be a full-fledged workable program). Any «round» of the solution, except for the first one, can be omitted without loss of functionality, and each block of the task can be independently evaluated by students. The paper provides an example of such a problem, describes in detail the stages of its solution, as well as the evaluation system. This technique has been tested at Samara State University of Social Sciences and Education with the students majoring in 44.03.01 Pedagogical Education («Computer Science»). The proposed method has shown good results both in the field of motivation and in terms of learning.

Keywords: education; pedagogical education; tasks; information and communication technologies (ICT); programming; higher education; project method; practice-oriented approach; programming language Python; tasks with spiral-increasing complexity; methods of teaching programming; programming paradigms.

\section{ПРИМЕНЕНИЕ ЛОГИЧЕСКИХ ОПОРНЫХ СХЕМ В КАЧЕСТВЕ СРЕДСТВА ПОВЫШЕНИЯ УРОВНЯ ЭКОЛОГИЧЕСКИХ ЗНАНИЙ СТУДЕНТОВ}

\section{(C) 2019}

Репин Денис Владимирович, кандидат биологических наук, доцент кафедры биоэкологии и химии

Чувашский государственный педагогический университет им. И.Я. Яковлева

$$
\text { (2. Чебоксары, Российская Федерачия) }
$$

Репина Надежда Васильевна, кандидат биологических наук, преподаватель

Чебоксарский кооперативный техникум Чувашпотребсоюза (г. Чебоксары, Российская Федераиия)

Аннотация. В данной статье описываются результаты экспериментальной работы по использованию логических опорных схем в качестве средства повышения экологических знаний студентов технолого-экономи- 
ческого и художественно-графического факультетов Чувашского государственного педагогического университета им. И.Я. Яковлева. Исследовательская работа осуществлялась с февраля 2019 года по май 2019 года. При осуществлении эксперимента студенты технолого-экономического факультета были выбраны в качестве контрольной группы, а студенты художественно-графического факультета - в качестве экспериментальной группы. В контрольной группе обучение осуществлялось без применения логических опорных схем. У студентов экспериментальной группы при осуществлении образовательного процесса использовались логические опорные схемы. Определение исходного уровня экологических знаний студентов обеих групп выявило близкие значения данного параметра. После проведения экспериментальной работы по внедрению логических опорных схем в учебный процесс было проведено повторное тестирование. Его результаты в обеих группах были выше, чем на начальном этапе эксперимента. В то же время при сравнении данных контрольной и экспериментальной групп выявлены существенные различия. У студентов, обучавшихся с применением логических опорных схем, баллы за тестирование были существенно выше, чем у студентов контрольной группы.

Ключевые слова: логические опорные схемы; опорные сигналы; В.Ф. Шаталов; экология; экологические знания; студент; экспериментальная работа; тестирование; средства наглядности; абстрактное мышление; конспектирование; теоретический материал; учебный процесс; Чувашский государственный педагогический университет им. И.Я. Яковлева.

\section{Введение}

Преподавание биологических дисциплин у студентов не биологических специальностей предполагает изучение большого объема материала при выделении небольшого объема часов на данные предметы. Данную проблему позволяет решить применение различных видов наглядности на лекционно-практических занятиях по данному циклу дисциплин. Они повышают интерес к изучаемым объектам и явлениям, облегчают процесс их усвоения, поддерживают внимание, мотивируют к саморазвитию и самообразованию [1-9].

Одним из видов наглядности являются логические опорные схемы. Данная технология позволяет охватить большой объем теоретического материала, оставляя время для отработки практических заданий. Логические опорные схемы помогают как конспектировать содержание темы на паре, так и готовить домашнее задание. Они способствуют усвоению большого количества теоретического материала, развивают абстрактно-логическое мышление и навыки самостоятельной работы студентов $[2 ; 10]$.

Методику использования в учебном процессе опорных сигналов разработал В.Ф. Шаталов [11-13]. Опорные сигналы представляют собой набор своеобразных символов, ассоциативных ключевых слов, знаков и других опор для мысли, расположенных особым образом, заменяющий некое смысловое значение. Он способен мгновенно восстанавливать в памяти известную ранее и понятную информацию. С помощью опорных сигналов создается модель теоретического материала. Опорные сигналы содержат знаки, значки, рисунки, ключевые слова, небольшие предложения. Необходимо, чтобы данные элементы содержали эмоционально окрашенный материал, который поможет закрепить в памяти необходимые элементы новый знаний [14].

Целью исследования явилось изучение влияния применения логических опорных схем на уровень экологических знаний студентов.

Для достижения данной цели были выдвинуты следующие задачи:

1) рассмотреть теоретические основы применения логических опорных схем как средства повышения уровня экологических знаний студентов;

2) изучить технологию составления логических опорных схем;

3) выявить исходный уровень экологических знаний студентов;

4) разработать и внедрить логические опорные схемы в учебный процесс;
5) оценить результаты применения логических опорных схем в качестве средства повышения уровня экологических знаний студентов.

\section{Материалы и методика исследований}

Изучение влияния применения логических опорных схем на уровень экологических знаний студентов осуществлялось в феврале - мае 2019 года на базе Чувашского государственного педагогического университета им. И.Я. Яковлева. Для определения эффективности внедрения логических опорных схем в учебный процесс среди студентов были выбраны контрольная и экспериментальная группы. В контрольной группе (студенты технолого-экономического факультета) обучение осуществлялось без применения логических опорных схем. У студентов экспериментальной группы (художественно-графический факультет) на занятиях использовались логические опорные схемы.

Экспериментальная работа по определению влияния логических опорных схем на уровень экологических знаний студентов состояла из следующих этапов:

1) констатирующий этап - определялся исходный уровень экологических знаний студентов обоих факультетов;

2) формирующий этап - в экспериментальном группе при объяснении материала применялись логические опорные схемы, а в контрольной группе обучение осуществлялось по традиционной методике без применения логических опорных схем;

3) контрольный этап - анализировался итоговый уровень экологических знаний студентов технологоэкономического и художественно-графического факультетов.

\section{Результаты исследований и их обсуждение}

Определение начального уровня экологических знаний студентов осуществлялось с помощью тестовых заданий, составленных на базе школьного материала. На констатирующем этапе экспериментальной работы при тестировании студентов обоих факультетов получены близкие результаты (рис. 1). Так, отметку «отлично» получили 10,5\% обучающихся контрольной группы и 8,3\% - экспериментальной. «Хорошо» было выставлено 26,3\% и 29,2\% студентов соответственно. 52,6\% студентов контрольной группы и 50\% - экспериментальной продемонстрировали удовлетворительный уровень экологических знаний. Необходимо отметить, что $10,5 \%$ студентов технолого-экономического факультета и $12,5 \%$ студентов 
художественно-графического факультета не справились с заданиями и получили оценку «неудовлетворительно». Таким образом, в контрольной группе средний балл за тестирование на констатирующем этапе эксперимента составил $3,365 \pm 0,819$, а в экспериментальной $-3,333 \pm 0,808$.

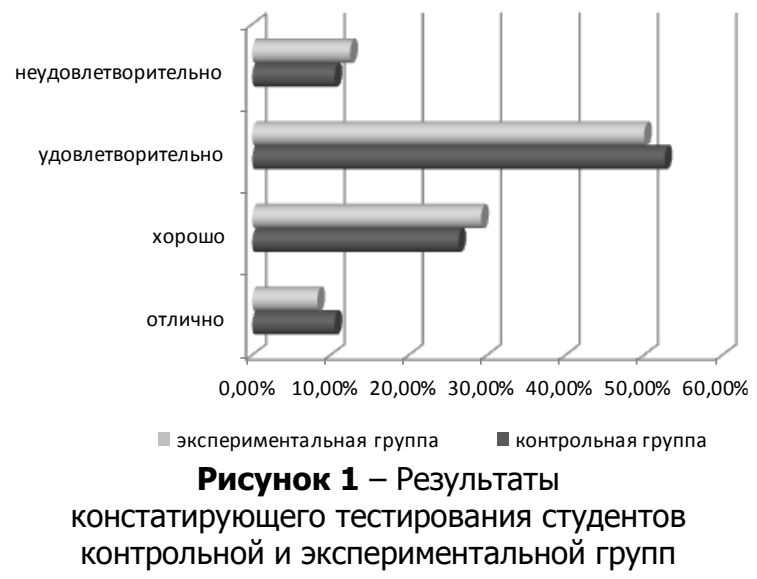

После проведения исходного тестирования студентов можно прийти к выводу о недостаточности экологических знаний обучающихся обеих исследуемых групп и необходимости их повышения. С этой целью в течение одного семестра на технолого-экономическом факультете Чувашского государственного педагогического университета им. И.Я. Яковлева изучение нового материала экологического содержания осуществлялось без использования логических опорных схем, а на художественно-графическом - с их применением.

На заключительном этапе эксперимента было проведено повторное тестирование студентов обоих факультетов по материалу, изученному на лекционнопрактических занятиях по экологии в вузе. На данном этапе между контрольной и экспериментальной группой уже наблюдались существенные различия. Так, у студентов технолого-экономического факультета (контрольная группа) результаты были несколько ниже по сравнению с ответами студентов художественнографического факультета (экспериментальная группа). Полученные данные представлены на рис. 2.

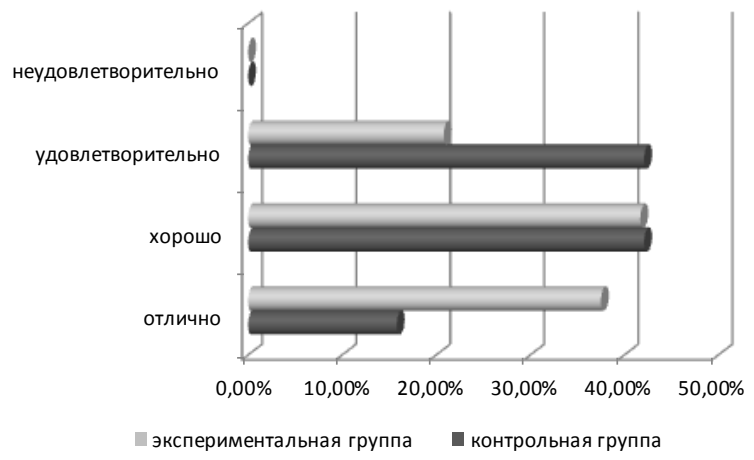

Рисунок 2 - Результаты повторного тестирования студентов контрольной и экспериментальной групп

Следует отметить, что в обеих исследованных группах после проведения занятий в течение второго семестра 2018/2019 учебного года не осталось студентов, не освоивших материал, то есть оценку «неудовлетворительно» не получил ни один студент. В то же время удовлетворительные знания показали $42,1 \%$ обучающихся контрольной группы и вдвое меньше студентов $(20,8 \%)$ - экспериментальной. На «хорошо» ответило одинаковое количество студен- тов как технолого-экономического $(42,1 \%)$, так и художественно-графического факультета $(41,7 \%)$. Отличные знания проявили $15,8 \%$ обучающихся контрольной группы. В экспериментальной группе данный показатель был более чем в два раза выше и составил 37,5\%. Средний балл за данное тестирование у студентов технолого-экономического факультета составил $3,737 \pm 0,724$, что на 0,372 балла выше, чем на констатирующем этапе эксперимента. У студентов художественно-графического факультета выявлены более выраженные различия между начальным и итоговым уровнями экологических знаний. Так, при повторном тестировании средний балл данной группы составил $4,167 \pm 0,753$, что на 0,834 балла выше, чем при исходной проверке знаний. Таким образом, если на констатирующем этапе эксперимента обучающиеся экспериментальной группы имели более низкие результаты уровня экологических знаний, нежели студенты контрольной группы, то после проведения эксперимента наблюдались противоположная ситуация.

\section{Выводы}

В результате исследования проблемы применения логических опорных схем в качестве средства повышения уровня экологических знаний студентов Чувашского государственного педагогического университета им. И.Я. Яковлева пришли к следующим выводам:

1. Установлено, что начальный уровень экологических знаний у студентов технолого-экономического и художественно-графического факультетов Чувашского государственного педагогического университета им. И.Я. Яковлева имеет сходные значения количественного соотношения обучающихся, получивших «отлично» (соответственно 10,5\% и 8,3\%), «хорошо» $(26,3 \%$ и $29,2 \%)$, «удовлетворительно» $(52,6 \%$ и $50 \%)$ и «неудовлетворительно» $(10,5 \%$ и $12,5 \%)$.

2. После изучения экологического материала в контрольной группе количество студентов, усвоивших материал на «отлично», увеличилось на 5,3\%, на «хорошо» - на 15,8\%, на «удовлетворительно» уменьшилось на 10,5\%. Обучающихся, не справившихся с тестовыми заданиями, на контрольном этапе эксперимента в данной группе не выявлено.

3. В экспериментальной группе после проведения курса лекционно-практических занятий с использованием логических опорных схем уровень экологических знаний студентов увеличился более существенно. Число обучающихся, сумевших ответить на «отлично», возросло на 29,2\%, на «хорошо» - на $12,55 \%$, на «удовлетворительно» - уменьшилось на $29,2 \%$. Как и в контрольной группе, студентов, не усвоивших пройденный материал, при повторном тестировании не обнаружено.

4. За период проведения экспериментальной работы средний балл за тестирование в контрольной группе увеличился на 0,372 балла, а в экспериментальной разница была более чем в два раза выше и составила 0,834 балла.

5. Применение логических опорных схем при организации лекционно-практических занятий у студентов Чувашского государственного педагогического университета им. И.Я. Яковлева способствует лучшему усвоению, запоминанию и воспроизведению экологического материала, позволяет организовать усвоение большого объема теоретического материала, развивать навыки самостоятельной работы студентов, способствует развитию их абстрактнологического мышления. 


\section{Список литературы:}

1. Репин Д.В., Репина Н.В. Анализ эффективности использования научно-исследовательской деятельности для формирования экологических знаний студентов // Биоэкологическое краеведение: мировые, российские и региональные проблемы / отв. ред. С.И. Павлов. Самара: СГСПУ, 2018. С. 313-315.

2. Репин Д.В., Семенов Л.В. Повышение уровня географических знаний обучающихся с помощью логических опорных схем // Природные и социальные экосистемы. Чебоксары: Чуваш. гос. пед. ун-т, 2019. C. $126-129$.

3. Репин Д.В., Якунина А.А. Формирование экологической культуры обучающихся во внеурочной деятельности // Природные и социальные экосистемы. Чебоксары: Чуваш. гос. пед. ун-т, 2019. С. 129-133.

4. Бирина О.В. Понятие успешности обучения в современных педагогических и психологических теориях // Фундаментальные исследования. 2014. № 8, ч. 2. C. $438-443$.

5. Вилюс В.К. Психологические механизмы мотивации человека. М.: Проспект, 2013. 170 с.

6. Курапова Т.Ю. Психологические факторы успешности обучения школьников // Ученые записки ЗабГГПУ. 2011. № 5 (40). С. 223-225.
7. Лоренц Д.В. Креативная педагогика на примере дисциплины: учеб.-метод. пособие. М.: Инфра-М, 2018. $252 \mathrm{c}$.

8. Шатунова Е.Ю. Создание ситуации успеха в учебно-воспитательном процессе // Концепт. 2014. T. 12. C. 206-210.

9. Щукина Г.И. Активация познавательной деятельности в учебном процессе. М.: Просвещение, 2015. $144 \mathrm{c}$.

10. Лапыгин Ю.Н. Методы активного обучения: учебник и практикум для вузов. М.: Юрайт, 2019. $248 \mathrm{c}$.

11. Шаталов В.Ф. Куда и как исчезли тройки: из опыта работы школ г. Донецка. М.: Педагогика, 1979. $134 \mathrm{c}$.

12. Шаталов В.Ф.Учить всех, учить каждого // Педагогический поиск. М.: Педагогика, 1989. 560 с.

13. Шаталов В.Ф. Эксперимент продолжается. Донецк: Сталкер, 1998. 396 с.

14. Калмыкова Н.В., Петряева С.Ф. Опорный конспект как один из способов представления учебной информации // Молодой ученый. 2015. № 11.1 (91.1). C. 53-58.

\section{THE USE OF LOGICAL REFERENCE SCHEMES \\ AS A MEANS OF INCREASING THE LEVEL OF STUDENTS' ENVIRONMENTAL KNOWLEDGE} (C) 2019

Repin Denis Vladimirovich, candidate of biological sciences, associate professor of Bioecology and Chemistry Department I. Yakovlev Chuvash State Pedagogical University (Cheboksary, Russian Federation)

Repina Nadezhda Vasilyevna, candidate of biological sciences, lecturer Cheboksary Cooperative Technical School of Chuvashpotrebsoyuz (Cheboksary, Russian Federation)

Abstract. This paper describes the results of experimental work on the use of logical support circuits as a means of increasing the environmental knowledge of students of technological, economic and graphic arts departments of I. Yakovlev Chuvash State Pedagogical University. The research was carried out from February 2019 to May 2019. During the experiment, students of Technology and Economics Department were selected as a control group, and students of Art and Graphics Department as an experimental group. In the control group, training was carried out without the use of logical support schemes. In the experimental group, the educational process used logical support schemes. The determination of the initial level of ecological knowledge of students of both groups revealed close values of this parameter. After the experiment on the logical reference circuits use in the educational process, a repeated testing was carried out. Its results in both groups were higher than at the initial stage of the experiment. At the same time, when comparing the data of the control and experimental groups, significant differences were revealed. The students who used logical support schemes had significantly higher test scores than the students of the control group.

Keywords: logical reference circuits; reference signals; V.F. Shatalov; ecology; environmental knowledge; student; experimental work; testing; visual aids; abstract thinking; note taking; theoretical material; studying process; I. Yakovlev Chuvash State Pedagogical University.

\section{ТЕХНОЛОГИЧЕСКИЙ ПРОЦЕСС ВНЕАУДИТОРНОЙ ИНДИВИДУАЛИЗАЦИИ ПОДГОТОВКИ ЗАРУБЕЖНЫХ МАГИСТРОВ УПРАВЛЕНИЯ ОБРАЗОВАНИЕМ}

Рыблова Алла Николаевна, доктор педагогических наук, профессор кафедры лингводидактики Московский государственный лингвистический университет (2. Москва, Российская Федерация)

Кан Цюнцюн, аспирант факультета педагогического образования

Московский государственный университет им. М.В. Ломоносова (2. Москва, Российская Федераиия)

Аннотащия. В статье ставится и решается проблема технологичной организации внеаудиторной индивидуальной деятельности зарубежных магистрантов. Технологичность индивидуализированного образователь- 